\title{
Sweating out the circadian rhythm: a technical review
}

Sayali Upashama, Nathan Kodjo Mintah Churchera, Paul Ricea, Shalini Prasada*

aDepartment of Bioengineering, University of Texas at Dallas, Richardson, TX-75080

${ }^{*}$ Corresponding author

History of the Development of Chronobiology Tracking

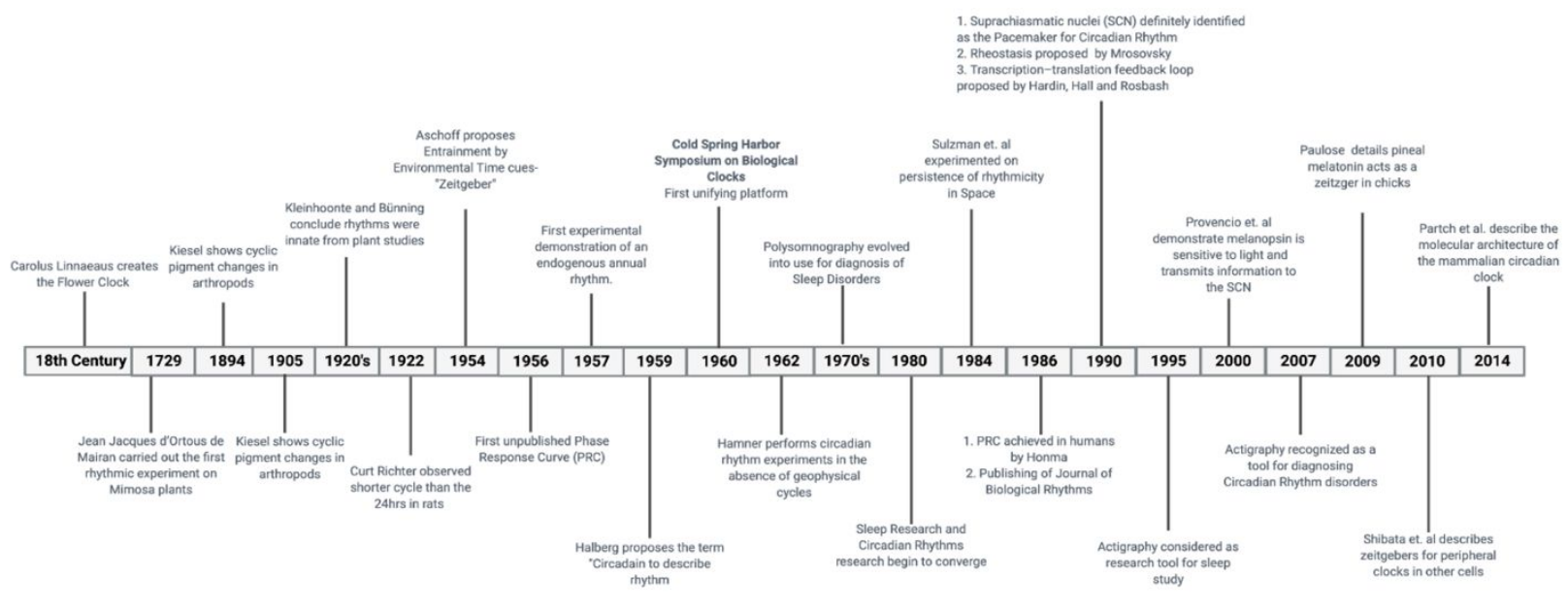

Figure S1: History of chronobiology, created with Biorender.com 